\title{
A POLÍTICA DE INOVAÇÃO E A FORMAÇÃO DO QUÍMICO
}

\author{
Sérgio de Paula Machado* \\ Instituto de Química, Universidade Federal do Rio de Janeiro, 21949-900 Rio de Janeiro - RJ, Brasil
}

Recebido em 29/10/12; aceito em 5/3/13; publicado na web em 6/5/13

\begin{abstract}
INNOVATION POLICY AND CHEMISTS' EDUCATION. In December 2004, Brazil's President signed Law number 10.973, which provides for incentives toward innovation, scientific and technological research in the production environment and other measures, also known as the Law of Innovation. Although Brazil has advanced greatly in the number of scientific articles published, currently accounting for about $3 \%$ of world scientific output, this progress has not been replicated in the production of patents. This article presents a discussion on the importance of introducing patent issues into national undergraduate courses.
\end{abstract}

Keywords: The Chemists' Education; undergraduate courses; patents.

\section{INTRODUÇÃO}

Em 2 de Dezembro de 2004 o Presidente Luiz Inácio da Silva sancionou a Lei $\mathrm{N}^{\circ} 10.973$, que dispõe sobre incentivos à inovação e à pesquisa científica e tecnológica no ambiente produtivo, também conhecida como Lei de Inovação. Esta Lei foi criada dentro de um contexto no qual o Brasil atingia um papel de destaque no cenário internacional de Ciência \& Tecnologia, sem, contudo, ter conseguido replicar esta evolução no número de depósitos de Patentes desenvolvidas em nosso país.

A Sociedade Brasileira de Química tem se destacado na discussão de como a Química Brasileira pode contribuir para o desenvolvimento Nacional. Entre as diversas ações, podemos destacar uma série de artigos publicados no suplemento especial do volume 28 da Revista Química Nova, de Novembro/ Dezembro 2005, com o título: "Necessidades e Perspectivas da Química no Brasil - O Futuro do Profissional na Pesquisa", dentro do convênio SBQ-CGEE. ${ }^{1} \mathrm{O}$ trabalho desenvolvido pela SBQ, no que tange à formação do Químico, ${ }^{2}$ contribuiu ativamente na construção das Diretrizes Curriculares dos Cursos de Química. Os documentos "Eixos Mobilizadores em Química" e "A Formação do Químico"4 são leituras obrigatórias para todos os Docentes que atuam na formação de profissionais de Química no Nível Superior, bem como dos atuais e futuros Coordenadores de Cursos de Graduação e PósGraduação. Além da elaboração de todo este material, disponível gratuitamente na página da Sociedade Brasileira de Química, a SBQ ainda realiza anualmente os Fóruns de Coordenadores de Graduação e de Pós-Graduação, mostrando sua importância no cenário nacional de formação de profissionais qualificados para o desenvolvimento do país. As revistas da Sociedade Brasileira de Química têm sido um canal dinâmico na difusão de informações relativas à área da Química, tanto em ensino e pesquisa quanto no desenvolvimento de questões relacionadas às patentes e à própria política de inovações. ${ }^{5}$ Entretanto, apesar deste esforço, quando pensamos na formação de nossos estudantes, ainda é possível encontrar uma lacuna relacionada ao conhecimento de propriedade industrial. Ao analisarmos os currículos dos cursos de graduação de nossas Universidades é possível constatar que tópicos que envolvam questões relativas à legislação não são apresentados aos nossos estudantes durante sua formação. Hoje existem cursos, de Tecnólogos e Bacharelados, que "formam" profissionais especializados em Química Ambiental que

*e-mail: sergiopm@iq.ufrj.br praticamente desconhecem as resoluções do CONAMA - Conselho Nacional de Meio Ambiente. Este problema não está restrito à questão ambiental, pois atinge outras áreas, entre elas a formação para o entendimento de questões relacionadas à propriedade industrial. Em uma breve avaliação qualitativa realizada em duas instituições Federais no Estado do Rio de Janeiro, durante as Semanas Acadêmicas, pode-se constatar que cerca de $90 \%$ dos estudantes dos cursos de graduação na área de Química nunca tiveram contato com uma patente. Além disto, desconheciam a legislação referente à propriedade industrial, definida pela Lei $\mathrm{N}^{\circ}$ 9.279, de 14 e Maio de 1996, conhecida como Lei da Propriedade Industrial, que regula direitos e obrigações relativos à propriedade industrial. Assim sendo, não tinham conhecimento do que poderia ser patenteado, confundindo patentes de invenção e de modelo de utilidade com direito autoral, por exemplo. Acredita-se que esta observação não seja restrita ao Estado do Rio de Janeiro, repetindo-se nos demais estados da Federação, com raras e louváveis exceções. Na verdade, de um modo geral, apesar de todo avanço atingido pela Química Brasileira, ainda temos currículos muito engessados, impedindo que abordagens modernas sejam contempladas e assumindo que as questões relacionadas à legislação sejam pertinentes apenas aos cursos de Direito. Entretanto, parece cristalino que é impossível formar um Químico sem nenhum conhecimento de legislação.

\section{DISCUSSÃO}

Se desejarmos contribuir para o esforço nacional, referente à política de inovação, temos que inserir nossos estudantes, de Graduação ou de Pós-Graduação, nos aspectos relacionados à política de inovação. Para tal, é necessário que a discussão a respeito de patentes seja disseminada nos diversos cursos na área da Química o mais rápido possível.

Mas afinal de contas, o que é uma patente?

Patente é o direito de explorar comercialmente uma invenção, com exclusividade, por tempo determinado. Segundo Francisco Teixeira: ${ }^{6}$ "A patente funciona como um fator de proteção que viabiliza os inventos na pesquisa científica". Assim sendo, parece claro que a inovação executada pela mão do homem é condição indispensável à aprovação de uma patente. Partindo deste princípio, outras questões surgem, por exemplo, o que pode ser patenteado? No artigo $8^{\circ}$ da Lei da Propriedade industrial (Lei ${ }^{\circ}$ 9.279/96) é definido que é patenteável a invenção que atenda aos seguintes critérios: NOVIDADE, ATIVIDADE INVENTIVA e APLICAÇÃO INDUSTRIAL. 
NOVIDADE - Significa que o produto deve ser realmente uma adição a todo o conhecimento preexistente, ou, uma adição ao ESTADO DA TÉCNICA. Podemos definir o Estado da Técnica como sendo: o conjunto de conhecimentos disponíveis no momento pré-existente da invenção. O Art. 11 da Lei no 9.279/96 descreve:

Art. 11. A invenção e o modelo de utilidade são considerados novos quando não compreendidos no estado da técnica. $\$ 1^{\circ} \mathrm{O}$ estado da técnica é constituído por tudo aquilo tornado acessível ao público antes da data de depósito do pedido de patente, por descrição escrita ou oral, por uso de qualquer outro meio, no Brasil ou no exterior, ressalvado o disposto nos artigos 12,16 e 17.

$\$ 2^{\circ}$ Para fins de aferição da novidade, o conteúdo completo de pedido depositado no Brasil, e ainda não publicado, será considerado estado da técnica a partir da data de depósito, ou da prioridade reivindicada, desde que venha a ser publicada, mesmo que subseqüentemente.

$\S 3^{\circ} \mathrm{O}$ dispositivo no parágrafo anterior será aplicado ao pedido internacional de patente depositado segundo tratado ou convenção em vigor no Brasil desde que haja processamento nacional.

ATIVIDADE INVENTIVA - Uma dada invenção tem que apresentar, necessariamente, originalidade e criatividade, não podendo ser uma simples reprodução de algo óbvio, ou seja, exige-se mais do que uma simples novidade, mas também que a invenção atinja certo nível de criatividade.

APLICAÇÃO INDUSTRIAL - A invenção deverá possuir características que permitam que esta seja produzida em escala industrial.

Logo, para que o invento seja patenteado é necessário que ele atenda a estes três quesitos: Novidade, Atividade Inventiva e Aplicação Industrial. Assim, um invento que não possa ser produzido industrialmente não pode ser patenteado. Tudo isto pode parecer muito simplório, mas com certeza é de desconhecimento da maioria dos alunos que estamos formando.

Outra consideração importante que consta na Lei de Patentes refere-se ao descrito no Artigo 24:

Art. 24. O relatório deverá descrever clara e suficientemente o objeto, de modo a possibilitar sua realização por técnico no assunto e indicar, quando for o caso, a melhor forma de execução.

Ou seja, há ainda a necessidade da existência da SUFICIÊNCIA DESCRITIVA. Assim, é possível compreender que o pedido de patente tem de ser acompanhado, necessariamente, por um relatório descritivo que permita ao técnico no assunto realizar aquilo que o inventor criou, de forma a garantir que, após o decurso do período de exclusividade garantido pela concessão da patente, que aquele invento possa ser reproduzido. Novamente surge um termo que merece esclarecimento, o que é um Técnico no Assunto? Um "TÉCNICO NO ASSUNTO" é aquele profissional com mediana experiência e conhecimento, e não um especialista ou técnico com elevadíssimo e vasto conhecimento na área. O técnico no assunto é, desta forma, a pessoa dotada de conhecimentos médios a respeito de um determinado assunto, e não o maior de todos os conhecedores da matéria ou um especialista em uma determinada área. Poderíamos supor que seria um Graduado com experiência mediana, sem formação em cursos de Pós-Graduação, seja Latu ou Stricto Sensu.

Mas note, como é possível, dentro destes parâmetros definidos pela Lei, compreender o que é uma Novidade? O próprio Instituto Nacional de Propriedade Industrial (INPI) elaborou um documento com as Diretrizes de Exame de Patentes. ${ }^{7}$ Neste documento o item 1.5.4 descreve que:

Se documentos de uma petição de subsídios já permitem uma decisão inequívoca baseada em falta de novidade, então o examinador emite parecer desfavorável. Para tanto, contudo, é necessário que toda a matéria do pedido seja claramente antecipada pelos documentos considerados e que não haja dúvida quanto à validade destes documentos como anterioridades. Como regra geral entende-se que há novidade sempre que a invenção ou modelo não é antecipado de forma integral por um único documento do estado da técnica. No exame de novidade uma reivindicação dependente não necessita definir matéria que por si só seja nova, uma vez que sua validade será sempre condicionada a uma leitura em conjunto com a ou as reivindicações de que depende. O requisito de atividade inventiva depende, necessariamente, da preexistência de novidade. Em não havendo novidade, não há sequer como se questionar a existência de atividade inventiva.

No caso de um documento (primeiro documento) referindo-se explicitamente a um outro documento que fornece informação mais detalhada sobre certas características, o ensinamento deste último documento deve ser considerado como incorporado ao primeiro documento que contém a referência.

Caso os documentos da petição de subsídios antecipem apenas parte da matéria reivindicada ou apenas algumas reivindicações, deverá ser dado seguimento ao exame com a realização da busca de anterioridades, antes que um parecer, exigência ou decisão seja proferido.

Logo, é possível se verificar que "Como regra geral entende-se que há novidade sempre que a invenção ou modelo não é antecipado de forma integral por um único documento do estado da técnica".

\section{CONCLUSÃO}

É importante ratificar que as informações presentes neste material são de domínio público, sendo as Leis e Diretrizes encontradas facilmente em buscas realizadas na Internet. Assim sendo, se é tão fácil encontrar todo este material, por que não discutí-los com nossos estudantes? Como podemos introduzir esta discussão nos cursos? Há a necessidade da criação de uma nova disciplina ou este é um tema transversal, passível de ser abordado nas diversas disciplinas existentes? Estes pontos merecem um amadurecimento e uma discussão urgente dentro da nossa comunidade a fim de atingirmos a meta de formar profissionais mais preparados para enfrentar as questões relacionadas à inovação. Desta forma, esta comunicação tem por objetivo estimular uma discussão ampla a este respeito, mostrando a importância de implementarmos, o mais rápido possível, questões relacionadas à patente nos cursos de Graduação. Certamente a Sociedade Brasileira de Química não se furtará em conduzir esta discussão.

\section{AGRADECIMENTOS}

Ao Dr. G. B. Pereira, Juiz da 25․ Vara Federal do Rio de Janeiro pelas discussões e pelo incentivo para que este artigo fosse redigido e a Dra. B. C. Machado pela discussão e pela crítica.

\section{REFERÊNCIAS}

1. Quim. Nova, 2005, 28 suplemento, $\mathrm{S} 1$. 
2. Zucco, C.; Pessine, F. B. T. ; Andrade, J.B.; Quim. Nova 1999, 22, 454.

3. Andrade, J.B.; Cadore, S.; Vieira, P.C.; Zucco, C.; Pinto, A.C.; Quim. Nova 2003, 26, 445

4. Andrade, J.B.; Cadore, S.; Vieira, P.C.; Zucco, C.; Pinto, A.C.; Quim. Nova, 2004, 27, 358

5. Rodrigues, A. de O.; Quim. Nova 1998, 21, 228; de Oliveira, L. G.; Suster, R.; Pinto, A. C.; Ribeiro, N. M.; da Silva, R. B.; Quim. Nova 2005, 28 suplemento, S36.; Miron, M.V.G.; Cavalcanti, F.D.B.;
Wongtschowski, P.; Quim. Nova 2005, 28 suplemento, S86; Soares, J. M.; Correa, M. C. D. V.; Quim. Nova 2010, 33, 1216; Speziali, M.G.; Guimarães, P.P.G.; Sinisterra, R.D.; Quim. Nova 2012, 35, 1700.

6. Teixeira, F.; Tudo o que você queria saber sobre patentes mas tinha vergonha de perguntar, Multimais Editorial Produções Ltda: São Paulo, 1997.

7. http://www.inpi.gov.br/images/stories/Diretrizes_doc_20_de_dez_verso_ final_26_dez.pdf, acessada em Dezembro de 2012. 